\title{
Foot Reflexology Effect on Postpartum Pain- A Randomized Clinical Trial
}

\author{
Galia Bakhtyari Nia¹, Simin Montazeri², Poorandokht Afshari³ ${ }^{3}$ Mohammad Hosein Haghighizadeh
}

${ }^{1}$ Department of Midwifery, Faculty of Nursing and Midwifery, Ahvaz Jundishapur University of Medical Sciences, Ahvaz, Iran. ${ }^{2}$ Department of Midwifery, Reproductive Health Promotion Research Center, Ahvaz Jundishapur University of Medical Sciences, Ahvaz, Iran. ${ }^{3}$ Reproductive Health Promotion Research Center, Ahvaz Jundishapur

University of Medical Sciences, Ahvaz, Iran. ${ }^{4}$ Department Biostatistics, School of Health, Ahvaz Jundishapur University of Medical Sciences, Ahvaz, Iran.

\section{ABSTRACT}

\section{BACKGROUND}

Postpartum pain is one of the most important and prevalent problems in the postpartum period. In this regard, reflexology is a common method to reduce this type of pain in women. Therefore, the present study was conducted to determine the effect of foot reflexology on postpartum pain.

\section{METHODS}

This randomized clinical trial study was conducted on mothers referred to obstetrics and gynaecology ward of Razi Teaching Hospital affiliated to Ahvaz Jundishapur University of Medical Sciences, Ahvaz, Iran from January to December 2018. A total of 68 women were randomly selected as per the inclusion criteria. Then, the participants were assigned to the intervention (n:34) and control (n:34) groups using a table of random digits. In the test group, reflexology was performed for 10 minutes on each foot in the pituitary points, the solar plexus points, the inner arch of the foot, and the uterine point. In the control group, routine care and other foot massages were performed. Data gathering tool in this study was a demographic questionnaire and pain visual analogue scale (VAS). The severity of pain was recorded immediately after the intervention, followed by 30, 60, 120 minutes, and 6 hours after the intervention. In case of intolerable pain, analgesic was prescribed to the mother until 30 minutes after the intervention. Data were analysed using descriptive statistics methods (mean and standard deviation), independent T-test, Kolmogorov-Smirnov, Chi-square, and Mann-Whitney tests using SPSS software version 22 .

\section{RESULTS}

The results showed that after foot reflexology, the mean score of pain intensity and duration were significantly decreased in the intervention group in comparison to control group ( $\mathrm{p}<0.001)$. Although the use of analgesic in the control group was at times more than the intervention group, it was not statistically significant $(\mathrm{p}=0.1)$ and the foot reflexology did not reduce the need for analgesic.

\section{CONCLUSIONS}

Based on the findings, foot reflexology is an effective and appropriate method for reducing the severity and duration of postpartum pain.

\section{KEY WORDS}

Postpartum, Pain, Foot Reflexology, Delivery, Complementary Medicine
Corresponding Author:

Simin Montazeri

Department of Midwifery,

Reproductive Health Promotion Research

Center, Ahvaz Jundishapur University of

Medical Sciences, Golestan Street,

Ahvaz, Khozestan, Iran.

Postal Code: 61357-15794.

E-mail: montazerisimin12@gmail.com

DOI: $10.14260 /$ jemds/2019/647

Financial or Other Competing Interests: This paper was part of the master's thesis of Galia Bakhtyari Nia, which was approved and financially supported by a grant (No: RHPRC-9605) from Research Affairs of Ahvaz Jundishapur University of Medical Sciences, Ahvaz, Iran.

How to Cite This Article:

Nia GB, Montazeri S, Afshari P, et al. Foot reflexology effect on postpartum pain- a randomized clinical trial. J. Evolution Med. Dent. Sci. 2019;8(39):2976-2981, DOI: 10.14260/jemds/2019/647

Submission 31-07-2019,

Peer Review 11-09-2019,

Acceptance 17-09-2019,

Published 30-09-2019. 


\section{BACKGROUND}

Childbirth is one of the most important events of every woman's life, So, satisfaction with the experience of childbirth is of great significance.(1) Postpartum pain is one of the most common and important problems associated with the contraction of uterus to return to the normal nonpregnant state. $(2,3,4)$ The secretion of inflammatory elements such as bradykinin, serotonin, cytokines, and prostaglandin which are released due to the tissue damage, contributed indirectly in this pain process. ${ }^{2}$ Postpartum pain is similar to severe menstrual cramps and occasionally is worse than delivery pain and usually lasts 3-4 days and rarely one week after delivery. ${ }^{(5)}$ According to the available statistical data nearly 500,000 American women experience postpartum pain annually, and one in 13 women suffers from severe postpartum pain after vaginal delivery.(6) The results of a study in England also showed that approximately $67 \%$ of women complain of pain in various parts of the body, especially in the lower abdomen and waist, up to ten days after delivery.(7) Melazack using the verbal pain chart showed that $30 \%$ of the primiparas and $58 \%$ of the multiparas experienced moderate to severe postpartum pain.(8)

Postpartum pain can lead to stress and neural-hormonal responses, anorexia, inability to do daily affairs, reduce mother's tolerance for infant feeding, anxiety, sadness, aggression, insomnia, lack of communication with the baby, and postpartum depression. ${ }^{(9)}$ The methods used today to control postpartum pain are divided into two general pharmaceutical and non-pharmacological groups.(10) One of the common nonpharmacological pain relief methods is the reflexology.(11) Reflexology is an effective healing method, which is a part of holistic science or complementary medicine. In this method, the therapist, with the use of pressure at the points of reflection in the legs and hands, which corresponds to each part of the body, causes the balance throughout the body and promote relaxation.(12) Based on reflexology treatment, these points link with the body organs and glands and have a structure and physical order similar to those of the body organs. Therefore, the feet and hands act like a mirror or a small map of the body, which stimulation of the reflex points on them can accurately affect the physical, emotional, and even mental health of individuals.(13) Although the exact action mechanism of the reflexology is still unclear, there are various theories in the efficacy of reflexology including energy channels theory, lactic acid theory, and neuromatrix pain theory.(14) However, considering the high prevalence of postpartum pain and its importance in maternal health and the mother's need for relaxation during breastfeeding, there has been no study on the efficacy of reflexology on postpartum pain. Regarding the safety of the non-invasive foot reflexology method to apply by midwives and supporting the complementary medicine, the present study was conducted to evaluate the effect of foot reflexology on reducing postpartum pain.

\section{METHODS}

\section{Ethical Considerations}

This randomized clinical trial was approved by the Ethics Committee of Ahvaz Jundishapur University of Medical
Sciences, Ahvaz, Iran (ethics code: IR.AGUMS.REC.1396.494), and registered in the Iranian Registry of Clinical Trials (IRCT) with IRCT20171208037792N1 code. To collect the data, the objectives of the study were explained to all participants and written informed consent was obtained from them. All participants had the right to withdraw from the study at any time.

\section{Study Design and Data Collection}

The present study was a randomized clinical trial with a control group. The study was performed on 68 randomly selected mothers who complained of moderate or severe postpartum pain after delivery and referred to the obstetrics and gynecology ward at Razi teaching hospital affiliated to Ahvaz Jundishapur University of Medical Sciences, Ahvaz, Iran from January to December 2018. The data gathering tool used in this study included a demographic information questionnaire of the pain Visual Analog Scale (VAS), a scale for measuring weight, a meter for measuring height, and a timer for measuring reflexology duration. Data were collected using a questionnaire consisted of quantitative (Age, body mass index, spouse's age, gravida, number of deliveries, abortion number, pregnancy week) and qualitative (Level of education, employment status, wife employment status, living area, ethnicity) demographic information.

\section{Randomization}

All participants were selected from Razi Teaching Hospital in Ahvaz city, southwest Iran. Randomization was initiated by evaluation of the presence of moderate or severe postpartum pain after delivery. On return from delivery room, women with moderate or severe postpartum pain were screened for the absence of secondary exclusion criteria and randomized 1:1 in two groups of the test ( 34 persons) and control (34 people) using a table of random digits.

\section{Sample Size Estimation}

To calculate the sample size, we used a routine method for clinical studies that was mentioned by Machin et al. (15) We utilized a $95 \%$ confidence interval, $90 \%$ power, and a 0.8 effect size. Accordingly, the sample size was determined to be 68 (34 control, 34 intervention) as calculated a priori with a t test using G Power package software.

\section{Inclusion and Exclusion Criteria}

The inclusion criteria were as follows: age range of 18-35, normal delivery, single baby, cephalic presentation, infant weight range between 2500 and 4000 grams, maternal complaint of moderate or severe postpartum pain (having a score of 3.1 or more based on pain scale ruler), second to fourth births, body mass index between (BMI) 18.9 and 29.9, and having reading and writing literacy. The exclusion criteria included long and hard labour, maternal addiction, history of postpartum haemorrhage, history of underlying illness (e.g., blood pressure, diabetes, and kidney problem), fetal death and stillbirth, analgesic consumption before intervention, severe stress (Separation, spouse's death) during the past 6 months, and any problems and lesions on the foot such as cornea, burns, cuts, fungal infections, varicose veins, warts, and numbness in the foot. 


\section{Subjects and Experimental Protocol}

The visual scale of pain intensity measurement was a $10 \mathrm{~cm}$ ruler. At the left and right ends of this ruler, the words of "painless" and "maximum pain" were written, respectively. The pain level in the last 48 hours was marked on the ruler. The pain level was measured by the researcher using the visual analogue scale, which is standardized for pain measurement. On this scale, the severity of pain is divided into three categories: mild (1-3), moderate (3.1-6), and severe (6.1-10).(16,17) In many studies, this questionnaire (because of its high validity and reliability) is used to assess the severity of pain applied to the patient. Bauer et al. studied the effect of massage therapy on pain, anxiety, and stress of postcardiac-surgery. They calculated the Cronbach's alpha coefficient for pain based on the internal consistency of this coefficient (0.89-0.99).(18)

After approving the research project and obtaining permission from the ethics committee of Ahvaz Jundishapur University of Medical Sciences, the researcher completed the demographic information questionnaire and visual analogue scale through interviews with the referring patients. Then, women having a score of 3.1 or more (According to the pain ruler) and other inclusion criteria were entered into the study with written consent. In the next step, the women were assigned to intervention (n:34) and control (n:34) groups using the four-block random number table. In the intervention group, after cleansing the legs, the subject was placed in the supine position with a small pillow under her feet for convenience. Then, a general massage was performed for 2 minutes on both legs. A non-aromatic oil (paraffin) was used to reduce the friction between the hands of the researcher and the feet of the subject. Pressure massage was performed at the pituitary points, the solar plexus points, the inner arch of the foot, and the uterine point. The pituitary point is located in the middle of the plantar surface of the thumb toe. If the foot is divided into three equal parts, the solar plexus point is located at the upper and middle one-third of the plantar surface of the foot in the part where the foot is folded up. The uterine point is located in the area between the inner ankles of the foot and the heel. The uterine point is located in the area between the medial malleolus and the heel. The massage time for each foot was 10 minutes and for both feet was 20 minutes. The severity of pain was recorded immediately after the intervention, followed by $30,60,120$ minutes, and 6 hours after the intervention using the VAS pain ruler. The duration of pain and the interval between the onset of the intervention and the mild pain in the mothers were evaluated by the researcher. Also, all routine cares were performed for both the control and test groups. In the case of intolerable pain, the analgesic was prescribed to the mother until 30 minutes after the intervention.

\section{Analysis of Data}

The data were analyzed based on descriptive statistics methods (Mean and standard deviation), independent T-test, Kolmogorov-Smirnov, Chi-square, and Repeated Measures tests using SPSS ${ }^{\mathrm{TM}}$ software version 22.0 (IBM Corporation, Armonk, NY, USA). Here, $\mathrm{p}<0.05$ was considered as the significance level.

\section{RESULTS}

All the 68 studied women met the inclusion criteria. A flow diagram of them is shown in Figure 1. According to Table 1, the median distribution of the variables of age, BMI, spouse age, number of pregnancies, number of deliveries, number of abortions, and the week of pregnancy both intervention and control groups showed no statistically significant difference ( $p>0.05$ ) using independent t-test.

In Table 2, qualitative demographic data were analysed in the intervention and control group and based on the results of the Chi-square test, there was no significant difference $(p<0.05)$ in terms of educational level, employment status, husband's employment status, current residence location, and the ethnicity of women in two groups.

According to Table 3 and Chi-square test results, there was no statistically significant difference in the frequency distribution of "decision to become pregnant", "history of back pain during pregnancy", "participation in the physiological delivery class", "type of onset of labour pain", "induction", "type of childbirth", and "gender of baby" variables in both groups $(\mathrm{p}<0.05)$.

\begin{tabular}{|c|c|c|c|}
\hline \multirow{2}{*}{ Gariable } & Intervention Group & Control Group & $\begin{array}{c}\text { p- } \\
\text { Value }\end{array}$ \\
\cline { 2 - 3 } & $28.50 \pm 3.29$ & $28.32 \pm 3.31$ & 0.826 \\
\hline Age & $27.35 \pm 1.56$ & $27.19 \pm 1.71$ & 0.686 \\
\hline BMI & $30.97 \pm 4.17$ & $30.06 \pm 4.01$ & 0.362 \\
\hline Spouse's age & $2.71 \pm 0.8$ & $2.74 \pm 0.67$ & 0.869 \\
\hline Gravida & $1.44 \pm 0.7$ & $1.53 \pm 0.61$ & 0.584 \\
\hline $\begin{array}{c}\text { Number of } \\
\text { deliveries }\end{array}$ & $0.29 \pm 0.46$ & $0.21 \pm 0.41$ & 0.408 \\
\hline Abortion number & $38.50 \pm 0.9$ & $38.76 \pm 1.16$ & 0.295 \\
\hline Pregnancy week & $\begin{array}{c}|c| \\
\text { Table 1. Distribution of Mean and Standard Deviation of Some } \\
\text { Quantitative Demographic Variables in both Intervention and } \\
\text { Control Groups }\end{array}$ \\
\hline
\end{tabular}

\begin{tabular}{|c|c|c|c|c|}
\hline \multirow{2}{*}{\multicolumn{2}{|c|}{$\mathrm{Pariable}_{\text {Group }}$}} & $\begin{array}{c}\text { Intervention } \\
\text { Group }\end{array}$ & $\begin{array}{c}\text { Control } \\
\text { Group }\end{array}$ & \multirow{2}{*}{$\begin{array}{c}\text { p- } \\
\text { Value }\end{array}$} \\
\hline & & \multicolumn{2}{|c|}{ Number (Percent) } & \\
\hline \multirow{4}{*}{$\begin{array}{c}\text { Level of } \\
\text { education }\end{array}$} & Elementary & $6(17.6)$ & $4(11.7)$ & \multirow{4}{*}{0.634} \\
\hline & Guidance & $7(20.6)$ & $5(14.7)$ & \\
\hline & High school & $11(32.4)$ & $16(47.1)$ & \\
\hline & Academic & $10(29.4)$ & $9(26.5)$ & \\
\hline \multirow{2}{*}{$\begin{array}{c}\text { Employment } \\
\text { status }\end{array}$} & Housewife & $27(79.4)$ & $22(64.7)$ & \multirow{2}{*}{0.177} \\
\hline & Employed & $7(20.6)$ & $12(35.3)$ & \\
\hline \multirow{4}{*}{$\begin{array}{c}\text { Wife } \\
\text { employment } \\
\text { status }\end{array}$} & Free & $13(38.2)$ & $12(35.3)$ & \multirow{4}{*}{0.732} \\
\hline & Employee & $8(23.5)$ & $5(14.7)$ & \\
\hline & Manual worker & $8(23.5)$ & $10(29.4)$ & \\
\hline & Unemployed & $5(14.7)$ & $7(20.6)$ & \\
\hline \multirow{2}{*}{ Living area } & City & $24(70.6)$ & $23(67.6)$ & \multirow{2}{*}{0.793} \\
\hline & Village & $10(29.4)$ & $11(32.4)$ & \\
\hline \multirow{4}{*}{ Ethnicity } & Fars & $5(14.7)$ & $5(14.7)$ & \multirow{4}{*}{0.543} \\
\hline & Lor & $6(17.6)$ & 11(32.4) & \\
\hline & Arab & $21(61.8)$ & $16(47.1)$ & \\
\hline & Turkish & $2(5.9)$ & $2(5.9)$ & \\
\hline
\end{tabular}

Table 2. Distribution of Absolute and Relative Frequency of the Examined Specimens by Some Qualitative Demographic Variables

Also, based on the results of independent T-test, there was no significant difference in the mean score of pain severity before intervention in two groups $(\mathrm{p}<0.05)$ (Table 4). After the intervention, the mean score of pain intensity in the intervention group was significantly lower than the control group immediately after the intervention, followed by 30,60 , 120 minutes, and 6 hours after the intervention $(\mathrm{p}<0.001)$. 


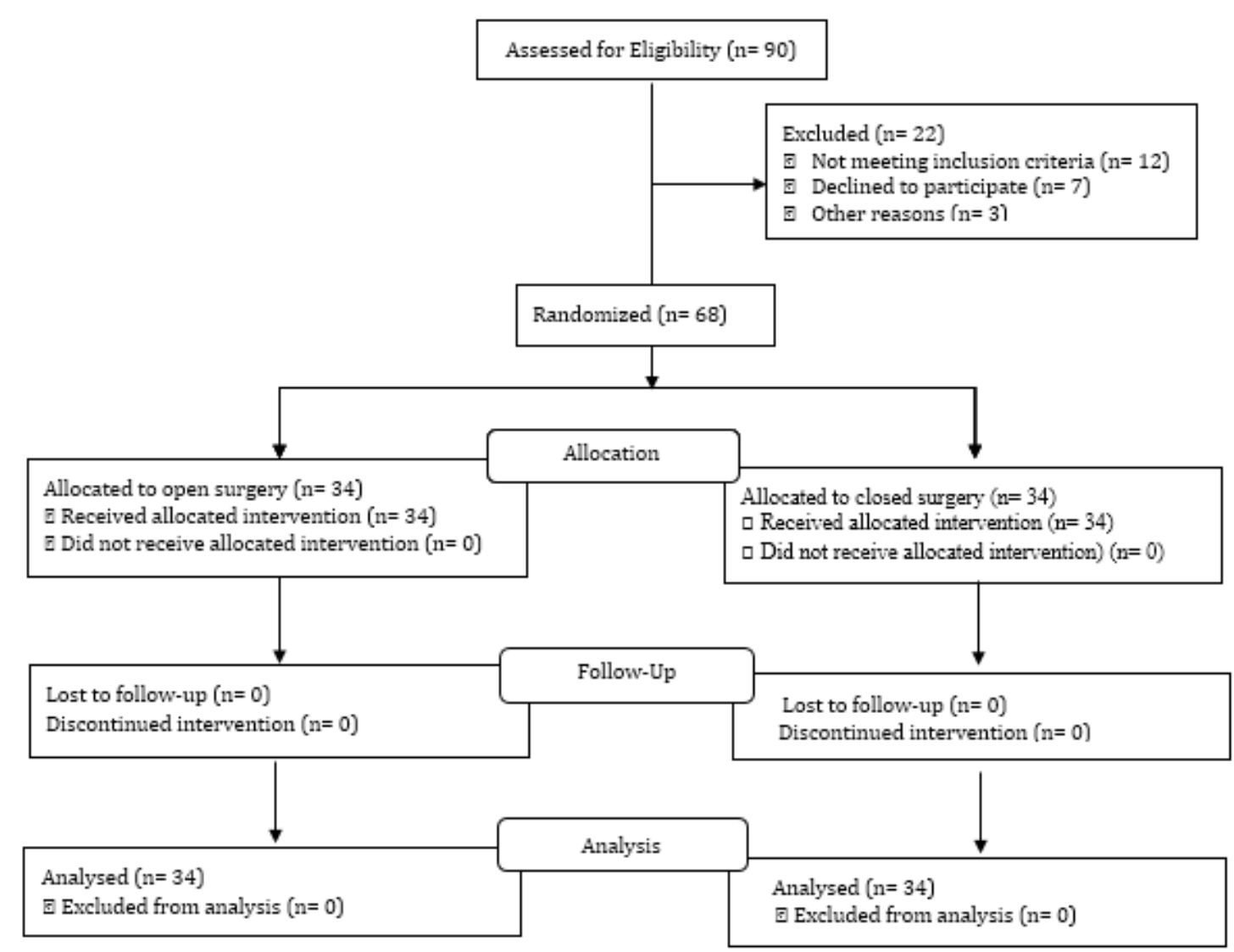

Figure 1. Consort Flow Diagram for Inclusion of Women with Postpartum Pain

\begin{tabular}{|c|c|c|c|c|}
\hline \multirow{2}{*}{\multicolumn{2}{|c|}{ Variable }} & $\begin{array}{c}\text { Intervent } \\
\text { ion } \\
\text { Group }\end{array}$ & $\begin{array}{l}\text { Control } \\
\text { Group }\end{array}$ & \multirow[t]{2}{*}{$\begin{array}{c}\text { p- } \\
\text { Value }\end{array}$} \\
\hline & & \multicolumn{2}{|c|}{ Number (Percent) } & \\
\hline \multirow{2}{*}{$\begin{array}{l}\text { Planning to become } \\
\text { pregnant }\end{array}$} & Wanted & $20(58.8)$ & $23(67.6)$ & \multirow{2}{*}{0.451} \\
\hline & Unwanted & $14(41.2)$ & $11(32.4)$ & \\
\hline \multirow{2}{*}{$\begin{array}{c}\text { A history ofbackpain } \\
\text { during pregnancy }\end{array}$} & Yes & $15(44.1)$ & $13(38.2)$ & \multirow{2}{*}{0.622} \\
\hline & No & $19(55.9)$ & $21(61.8)$ & \\
\hline \multirow{2}{*}{$\begin{array}{c}\text { Participate in the } \\
\text { physiological delivery class }\end{array}$} & Yes & $4(11.8)$ & $10(29.4)$ & \multirow{2}{*}{0.072} \\
\hline & No & $30(88.2)$ & $24(70.6)$ & \\
\hline \multirow{2}{*}{ Type of onset of labour pain } & Induction & $4(11.8)$ & $4(11.8)$ & \multirow{2}{*}{$<0.999$} \\
\hline & Automatically & $30(88.2)$ & $30(88.2)$ & \\
\hline \multirow{2}{*}{ Induction } & Yes & $13(38.2)$ & $10(29.4)$ & \multirow{2}{*}{0.442} \\
\hline & No & $21(61.8)$ & $24(70.6)$ & \\
\hline \multirow[b]{2}{*}{ Type of delivery } & Normaldelivery & $20(58.8)$ & $26(76.5)$ & \multirow[b]{2}{*}{0.120} \\
\hline & $\begin{array}{l}\text { Natural delivery } \\
\text { with episiotomy }\end{array}$ & $14(41.2)$ & $8(23.5)$ & \\
\hline \multirow{2}{*}{ Babygender } & Boy & $23(67.6)$ & $19(55.9)$ & \multirow{2}{*}{0.318} \\
\hline & Girl & $11(32.4)$ & $15(44.1)$ & \\
\hline
\end{tabular}

\begin{tabular}{|c|c|c|c|}
\hline Gariable & $\begin{array}{c}\text { Intervention } \\
\text { Group }\end{array}$ & $\begin{array}{c}\text { Control } \\
\text { Group }\end{array}$ & \multirow{2}{*}{ p-Value } \\
\cline { 2 - 3 } & \multicolumn{2}{|c|}{ Mean \pm SD } & \\
\hline $\begin{array}{c}\text { Severity of pain before } \\
\text { intervention }\end{array}$ & $7 \pm 0.95$ & $7.06 \pm 0.92$ & 0.796 \\
\hline $\begin{array}{c}\text { Severity of pain immediately } \\
\text { after intervention }\end{array}$ & $4.79 \pm 1.15$ & $6.5 \pm 1.11$ & $<0.001$ \\
\hline $\begin{array}{c}\text { Severity of pain 30 minutes after } \\
\text { intervention }\end{array}$ & $4.12 \pm 1.12$ & $5.91 \pm 1.14$ & $<0.001$ \\
\hline $\begin{array}{c}\text { Severity of pain 60 minutes after } \\
\text { intervention }\end{array}$ & $2.62 \pm 1.65$ & $5.24 \pm 1.28$ & $<0.001$ \\
\hline $\begin{array}{c}\text { Severity of pain 120 minutes } \\
\text { after intervention }\end{array}$ & $1.79 \pm 1.45$ & $4.06 \pm 1.61$ & $<0.001$ \\
\hline $\begin{array}{c}\text { Severity of pain 6 hours after } \\
\text { intervention }\end{array}$ & $1.18 \pm 1.17$ & $3.41 \pm 1.37$ & $<0.001$ \\
\hline p-Value & $<0.001$ & $<0.001$ & \\
\hline $\begin{array}{c}\text { Table 4. Distribution of Pain Severity at Different Time Intervals } \\
\text { in the Intervention and Control Groups }\end{array}$ \\
\hline \multicolumn{4}{|c|}{} \\
\hline \multicolumn{4}{|c|}{}
\end{tabular}

\begin{tabular}{|c|c|c|c|c|}
\hline \multirow{2}{*}{ Gariable } & \multirow{2}{*}{ Group } & $\begin{array}{c}\text { Intervention } \\
\text { Group }\end{array}$ & $\begin{array}{c}\text { Control } \\
\text { Group }\end{array}$ & \multirow{2}{*}{$\begin{array}{c}\text { p- } \\
\text { Value }\end{array}$} \\
\cline { 3 - 4 } & Number (Percent) & \\
\hline \multirow{2}{*}{$\begin{array}{c}\text { Taking } \\
\text { Mefenamic Acid }\end{array}$} & Yes & $3(8.8)$ & $8(23.5)$ & \multirow{2}{*}{0.1} \\
\cline { 2 - 4 } Table 5. Frequency Distribution of Mefenamic Acid Intake in the \\
both Intervention and Control Groups \\
\hline \multicolumn{3}{|c|}{} \\
\hline
\end{tabular}

The repeated measures test showed a significant decrease in pain intensity after intervention in both groups. Although the mean score of pain intensity in the intervention and control groups dropped from 7 to 1.18 and from 7.06 to 3.41 , respectively, however, the decrease in pain intensity in intervention group was more significant compared to the control group $(\mathrm{p}<0.001)$. Besides, the duration of pain in the intervention group (Mean \pm SD : $63.37 \pm 7.99$ ) showed a significant decrease compared to the control group (Mean \pm SD : $233.14 \pm 52.37)(p<0.001)$. The results of the chi-square test on "mefenamic acid consumption" also showed that there was no statistically significant difference in the control and test intervention groups $(\mathrm{p}=0.1)$ (Table 5).

\section{DISCUSSION}

The present study aimed to evaluate the effect of foot reflexology on postpartum pain reduction. The results of this study showed that there was a significant reduction in postpartum pain after foot reflexology such that, immediately after the intervention, the pain intensity score in the intervention group was in the range of moderate pain. 
However, the pain intensity score in the control group was still within the range of severe pain. This difference indicated that foot reflexology had a significant effect immediately after the intervention. Six hours after the intervention, the pain intensity levels in the intervention and control groups were $1.18 \pm 1.37$ and $3.41 \pm 1.37$, respectively. This descending trend indicated that even after 6 hours of intervention, the control group still suffered from moderate pain, while the reflexology group did not report moderate pain after the 60th minute and had a mild pain score. This difference in mean pain intensity score was statistically significant in both groups. In reviewing the available literature on the analgesic effects of reflexology, Irani et al. in mashhad (Iran),(19) Elfattah et al. in Egypt,(20) Haji ghasemali et al. in Tehran (Iran),(21) Dolatyan et al. in Tehran (Iran), (22) Janabi et al. in Hamedan (Iran), (23) as well as Mirzaee et al. in Kerman (Iran) ${ }^{(24)}$ concluded that foot reflexology has been effective in reducing the severity of postpartum pain. In addition to pain relief, reflexology is also effective in other cases such as improving the first- and fifth-minute Apgar in the newborns, reducing postpartum haemorrhage, (25) and reducing maternal anxiety during labor.(26) Several studies have also been conducted on the effect of this method on reducing caesarean section pain. Rezaei et al.(27) Khoshterash et al.(28) Razmjou et al,(29) Abbaspour et al(30) Xue et al.(31) showed that the use of reflexology and massage of hands and feet was effective in reducing postpartum pain after caesarean delivery. However, Keslering in Germany reported that the post-caesarean pain in the reflexology group was more than the control group.(24) Also, reflexology and massage of hands and feet have been effective in reducing anxiety and correcting physiological parameters (Blood pressure, respiration, and pulse) after caesarean section.(28,31) Postpartum pain due to fast and intermittent uterine contractions and secretion of chemical mediators of pain ${ }^{(3,7)}$ is similar to the mechanism of pain in dysmenorrhea. Therefore, to explain the effect of foot reflexology on postpartum pain, the literature on the effect of reflexology on the severity of dysmenorrhea has been used. Funda Demirturk, ${ }^{(32)}$ and Valiani et al.(33) showed that foot reflexology could reduce the severity of dysmenorrhea in the reflexology group. Investigating the second goal of the study, it was found that the mean duration of pain in the intervention group was $63.97 \pm 37.99$ minutes versus $223.52 \pm 141.37$ minutes in the control group. Therefore, the foot reflexology could dramatically reduce the mean duration of pain. Moghimi et al. showed that reflexology could decline the duration of labour stages.(34) These results are in line with the findings of the present study. In another study, Jenabi et al. reported that although reflexology could reduce the severity of labour pain, it did not affect the duration of labour.(23)

Regarding the effect of reflexology on the need for postpartum analgesics, it was found that $23.5 \%$ of the control group compared with $8.8 \%$ in the intervention group needed to use analgesics regarding postpartum relief. Although the need for analgesics in the control group was 3 times more than that of the intervention group, this difference was not statistically significant. These results may suggest that the decrease in the severity and duration of delivery by reflexology and decreased need for analgesics in the intervention group. However, it seems that due to the analgesic effects of massage in other parts of the body in the control group, this difference is not significant. The results also showed that 6 hours after intervention, about half of the subjects in the control group suffered from moderate pain and had an indication for analgesics, but refused to use it. Probably, participants were reluctant to take analgesic due to the effects of medication on breastfeeding and themselves and therefore sought alternative and complementary therapies. One of the most important strengths of this study is to examine the severity and duration of postpartum pain in labour for up to 6 hours after the intervention. Regarding the methods of other studies related to the effect of reflexology on pain intensity, there were few studies in which pain intensity was assessed up to 6 hours after the intervention. The limitations of this study include the inability of the researcher to confirm the validity of the statements of the subjects, the subjectivity of the pain experience, and the effects of environmental, personal, genetic, mental, and psychological factors on the threshold of pain.

\section{CONCLUSIONS}

Foot reflexology is an effective way to reduce the severity and duration of postpartum pain. Therefore, it is recommended for relieving postpartum pain because of its convenience, effectiveness, low cost, safety, and absence of complications.

\section{ACKNOWLEDGEMENT}

This paper was part of the master's thesis of Galia Bakhtyari Nia, which was approved and financially supported by a grant (No: RHPRC-9605) from Research affairs of Ahvaz Jundishapur University of Medical Sciences, Ahvaz, Iran. The authors would like to thank the Vice-Chancellor for Research and Technology of Ahvaz Jundishapur University of Medical Sciences, officials and employees of the Department of Obstetrics and Gynaecology at Ahvaz Razi Hospital, and all the mothers who participated in this study.

\section{REFERENCES}

[1] Cunningham F, Leveno $\mathrm{K}$, Bloom S, et al. Williams Obstetrics. 22 $2^{\text {nd }}$ edn. New York: McGraw-Hill Publication 2005.

[2] Fahey JO. Best practices in management of postpartum pain. J Perinat Neonat Nurs. 2017;31(2):126-136.

[3] Bijl RC, Freeman LM, Weijenborg PT, Middledrop JM, Dahan A, van Dorp EL. A retrospective study on persistent pain after childbirth in the Netherlands. J Pain Res. 2016;9:1.

[4] Chen SF, Wang CH, Chan PT,Chiang HW, Hu TM, Tam KW, Loh EW. Labour pain control by aromatherapy:A metaanalysis of randomized controlled trials. Women Birth.2019;32(4):327-335.

[5] Taffazoli M, Khadem Ahmadabadi M. Assessment of factors affecting afterpain in multiparous women delivered in Mashhad 17-Shahrivar Hospital, Mashhad,Iran. JMRH. 2014;2(1);60-65. 
[6] Beyhagh. The severity of acute pain after childbirth, regardless of the type of delivery, persistence of chronic pain. J Sabzevar Univ Med Sci 2009;19(1):25-31.

[7] Holdcroft A, Snidvongs S, Cason A, et al. Pain and uterine contractions during breast feeding in the immediate post-partum period increase with parity. Pain 2003;104(3):589-96.

[8] Melzack R. The myth of painless childbirth (the John J. Bonica lecture). Pain 1984;19(4):321-37.

[9] Eastman N, Hellman L. Williams Obstetrics $12^{\text {th }}$ edn. New York: McGraw-Hill Publication 2010: p. 1-81.

[10] Czech I, Fuchs P, Fuchs A, et al. Pharmacological and nonpharmacological methods of labour pain reliefestablishment of effectiveness and comparison. Int $\mathrm{J}$ Environ Res Public Health 2018;15(12):E2792.

[11] Rahimi F, Goli S, Soltani N, Rezaei H, Amouzeshi Z. Effects of complementary therapies on labor pain; A literature review. Mod Care J. 2018;15(1):e69306.

[12] Rahimi F, Goli S, Soltani N, Rezaei H, Amouzeshi Z. Effects of complementary therapies on labor pain; A literature review. Mod Care J. 2018;15(1):e69306.

[13] Embong NH, Soh YC, Ming LC, et al. Perspectives on reflexology: a qualitative approach. J Tradit Complement Med 2016;7(3):327-31.

[14] Unlua A, Kirca O, Ozdogan M. Reflexology and cancer. J Oncol Sci 2018;4(2):96-101.

[15] Machin D, Campbell M, Tan BT, et al. Sample size tables for clinical studies. Chap - 5. $3^{\text {rd }}$ edn. Wiley-Blackwell 2009: p. 57.

[16] Hockenberry MJ, Wilson D. Wong's essentials of pediatric nursing. $9^{\text {th }}$ edn. Elsevier Health Sciences 2013.

[17] Butchibabu K, Koppolu P, Tupili MK, et al. Comparative evaluation of gingival depigmentation using a surgical blade and a diode laser. J Dent Lasers 2014;8(1):20-5.

[18] Bauer BA, Cutshall SM, Wentworth LJ, et al. Effect of massage therapy on pain, anxiety and tension after cardiac surgery: a randomized study. Complement Ther Clin Pract 2010;16(2):70-5.

[19] Irani M, Kordi M, Tara F, et al. The effect of hand and foot massage on post-cesarean pain and anxiety. J Midwifery Reprod Health 2015;3(4):465-71.

[20] Elfattah AH, Metwaly S, Khedr N, NFH. Outcomes of foot reflexology on the pain and certain features of the labor for the primiparous women. Life Sci J 2015;12:206-16.

[21] Hajighasemali S, Sedegheh AAA, Baghban ARA, et al. Comparison of the effect of acupressure in spleen 6 and foot reflexology on pain intensity of the first stage of labor. Par J Med Sci 2015;12(4):15-22.
[22] Dolatian M, Hasanpour A, Heshmat R, et al. The effect of reflexology on pain intensity of labor. Zanjan Univ Med Sci Jour 2010;18(72):52-61. (Persian).

[23] Jenabi E, Mohajeran HM, Torkamani M. The effect of reflexology on relieving the labor pain. Iran J Obstet Gynecol Infertil 2012;14(8):34-8.

[24] Mirzaee F, Kaviani M, Jafari P. Effect of reflexology on anxiety level in Nuliparous women. Hayat 2010;16(1):65-71.

[25] Hanjani M, Tourzani MZ, Shoghi, et al. The effect of foot reflexology on the severity of pain and the length of delivery stages in Primiparous women. Komesh 2013;14(2):166-71.

[26] Erkek YZ, Aktas S. The effect of foot reflexology on the anxiety levels of women in labor. J Altern Complement Med 2018;24(4):352-60.

[27] Rezaei R, Saatsaz S, Alipour A, et al. Massage-therapy and post cesarean pain control. Iran J Obstet Gynecol Infertil 2017;20(4):34-43.

[28] Khoshtarash M, Ghanbari A, Yegane MR, et al. Effects of foot reflexology on pain and physiological parameters after cesarean section. Koomesh 2012;14(1):109-16.

[29] Razmjoo N, Yousefi F, Esmaeeli H, et al. Effect of foot reflexology on pain and anxiety in women following elective cesarean section. Iran J Obstet Gynecol Infertil 2012;15(1):8-16.

[30] Saatsaz S, Rezaei R, Alipour A, et al. Massage as adjuvant therapy in the management of post-cesarean pain and anxiety: a randomized clinical trial. Complement Ther Clin Pract 2016;24:92-8.

[31] Xue M, Fan L, Ge L, et al. Postoperative foot massage for patients after caesarean delivery. Z Geburtshilfe Neonatol 2016;220(04):173-8.

[32] Demirtürk F, Erkek ZY, Alparslan Ö, et al. Comparison of reflexology and connective tissue manipulation in participants with primary dysmenorrhea. J Altern Complement Med 2016;22(1):38-44.

[33] Valiani M, Babaei E, Heshmat R, et al. Comparing the effects of reflexology methods and Ibuprofen administration on dysmenorrhea in female students of Isfahan University of Medical Sciences. Iranian J Nursing Midwifery Res 2010;15(Suppl 1):371-8.

[34] Moghimi-Hanjani S, Mehdizadeh-Tourzani Z, Shoghi M. The effect of foot reflexology on anxiety, pain and outcomes of the labor in Primigravida women. Acta Med Iran 2015;53(8):507-11. 